\section{USE OF VIBRODIAGNOSTICS TO PREDICT PHENOMENA IN SERIAL AUTOMOTIVE
PRODUCTION}

ANTON PANDA ${ }^{1}$, SAMUEL CEHELSKY ${ }^{1}$

${ }^{1}$ Technical University of Kosice, Department of Automotive and Manufacturing Technologies, Faculty of Manufacturing Technologies with a seat in Presov, Slovak Republic

DOI: 10.17973/MMSJ.2021_10_2021017

e-mail: anton.panda@tuke.sk

The paper discusses the use of vibrodiagnostics in automotive production. Describes the Fast Fourier Transformation and its importance in evaluating the measured values. It focuses on the process of honing the toothing of shafts used in seriesproduced gearboxes. Describes 3 different states of amplitude with consideration to the set limit. In the first state, all production criteria are met. In the second state, the limit is exceeded and the specific error and its impact on the continuation of production are described. The third state describes the extreme crossing of the limit and the consequences for this state. Finally, the importance and practicality of the method for predicting production conditions are summarized.

Vibrodiagnostics, Fourier transformation, DFT, FFT

KEYWORDS

\section{INTRODUCTION}

Measurement, recording and analysis of mechanical vibration are an integral part of the diagnostic system for monitoring the operating conditions of machines throughout the industry. The aim is to find the causes of oscillations and the possibility of their elimination.

Vibrations are measured because they affect the life of machines and structures, but also the assessment of its harmful effect on humans, whether in the form of noise or vibration, which are closely related. Increased vibrations in most cases generate noise that spreads to the surroundings. Noise is the original phenomenon of vibrations, which in technical equipment causes material stress leading to direct failure. Vibration measurement is usually combined with measurement of other diagnostic variables such as speed, temperature, torque, operating pressure, machine start and stop parameters. Vibration can be imagined as the oscillation of a mechanical system, which represents the movement of a flexible body or environment whose individual points oscillate around its equilibrium position. Their monitoring and evaluation is one of the basic and crucial methods of technical diagnostics. Early detection of a possible defect is then a basic prerequisite for strategic planning of corrective measures. Vibrations can be described by amplitude and phase at a given point in time [Straka 2018a,b, Molnar 2019].

The vibrations are mostly random in nature and are composed of many frequency components, which describes the spectral power density, which is always related to a certain bandwidth. The effects of vibrations can be assessed from their amplitude, time course, frequency or spectrum. In the range of acoustic frequencies (audible) we refer to waves in a gaseous or liquid environment as sound, mechanical waves (oscillations) in solids as vibrations [Kreidl 2006, Krenicky 2012].

In the case of mechanical oscillations, the values of the determining quantities of oscillations (deflections, velocities, accelerations) constantly change over time, and energies are converted. We therefore say that mechanical vibration is a dynamic process. If we are interested in the time course of oscillations of a certain body, we must examine its kinematic conditions [Panda 2014, 2018a,b and 2019, Valicek 2016 and 2017, Macala 2009 and 2017, Pandova 2018, Balara 2018, Monkova 2013, Gombar 2013, Bielousova 2017, Dyadyura, 2017, Duplakova 2018, Bozek 2021, Flegner 2019 and 2020, Mrkvica 2012, Modrak, 2019, Peterka 2018, Pollak 2020a,b, Olejarova 2017 and 2019, Rimar 2016, Zaborowski 2007, Michalik 2014].

When we are interested in the causes of oscillations, we must investigate the equation of balance of forces and moments acting on the system. The position of a rigid body or mass point in space is determined by its position vector. If we determine at any time the amplitude (magnitude) and phase of this vector, we are able to describe their mechanical oscillation. We also calculate shocks for mechanical oscillations. These involve the collision of two bodies moving relative to each other, this collision causing a transient phenomenon, a shock [Smetana 1998].

\section{FOURIER TRANSFORMATION}

A Fourier transform is a transform that maps the functions of a real variable. This operation is performed every time we hear different sounds. The ear performs an automatic "calculation", which our consciousness is able to do only after studying the relevant part of higher mathematics. The organ of hearing in humans creates a transformation, resulting in sound (oscillating motion of conditioned particles in an elastic medium that propagates in wave form in a solid, liquid or gaseous medium) in the form of a spectrum of successively reaching tones of different pitches. Then the brain turns this information into a sound that is known to everyone [Dillinger 2007].

The transformation of sound waves or other oscillating processes (from light radiation and ocean tides to stellar or solar activity cycles) can be performed using mathematical methods. So with these techniques you can divide functions by presenting oscillating processes using a set of sine components, that is, wave-like curves that go from minimum to maximum, then again to minimum, like a sea wave. A Fourier transform is a transform whose function describes the phase or amplitude of each sinusoid corresponding to a specific frequency. The phase is the starting point of the curve and the amplitude is its height [Dillinger 2007].

\section{DESCRIPTION OF STATES}

When determining the diagram and its results, we can define two states. Positive and negative. this result depends on the workers and their ability to evaluate the assessed diagrams. However, this requires certain preparatory steps that must be completed before introducing diagnostics. An important factor is the prevention of unwanted vibrations from the environment, best to isolate the machine on which operations are performed and vibration diagnostics is applied. if this condition is not met, the conditions may be distorted and thus all diagnostics unsuitable for such a production process. First, the system needs to be prepared to know when and what components to classify and evaluate as unsuitable for further use. 


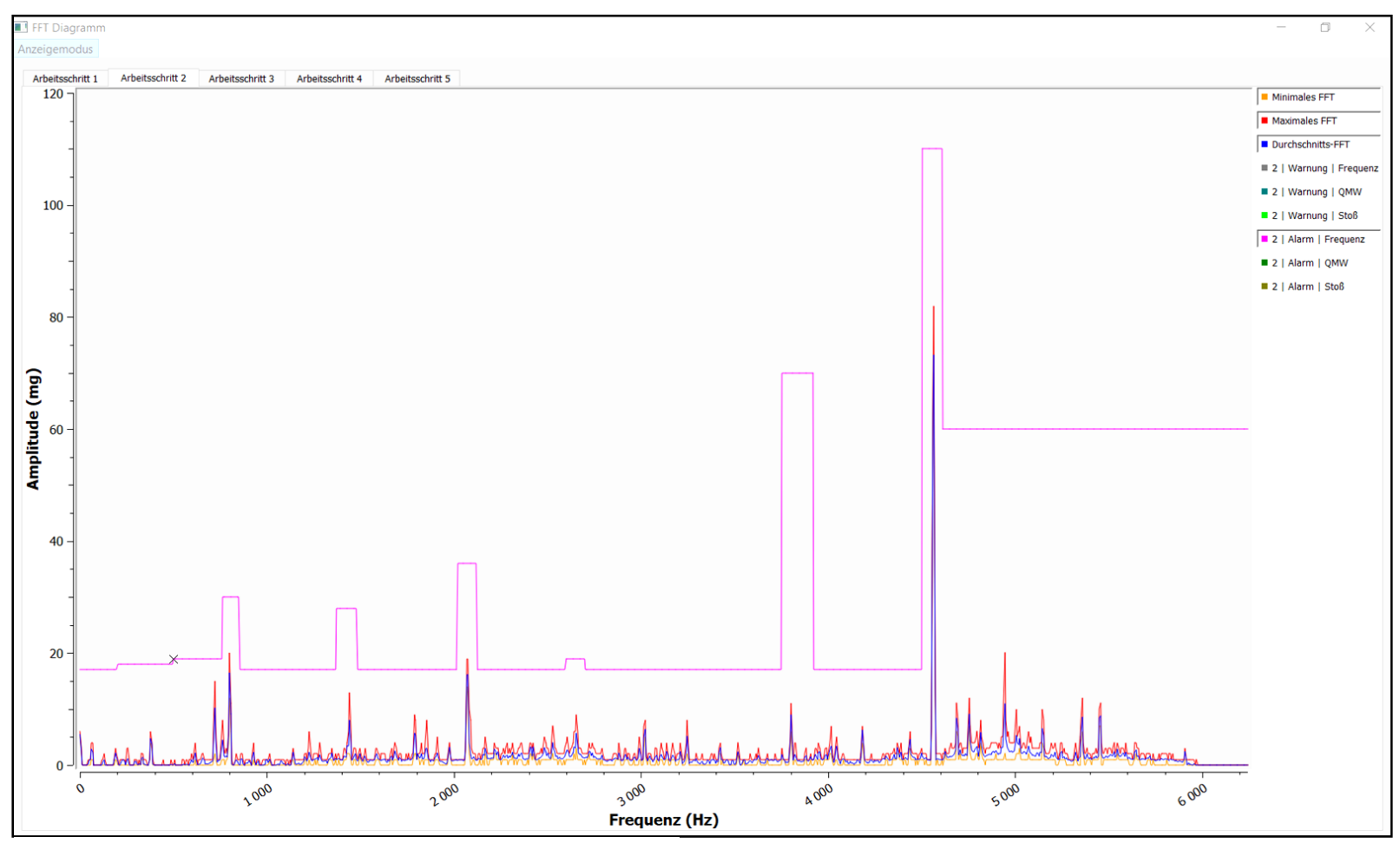

Figure 1. Diagram for OK part

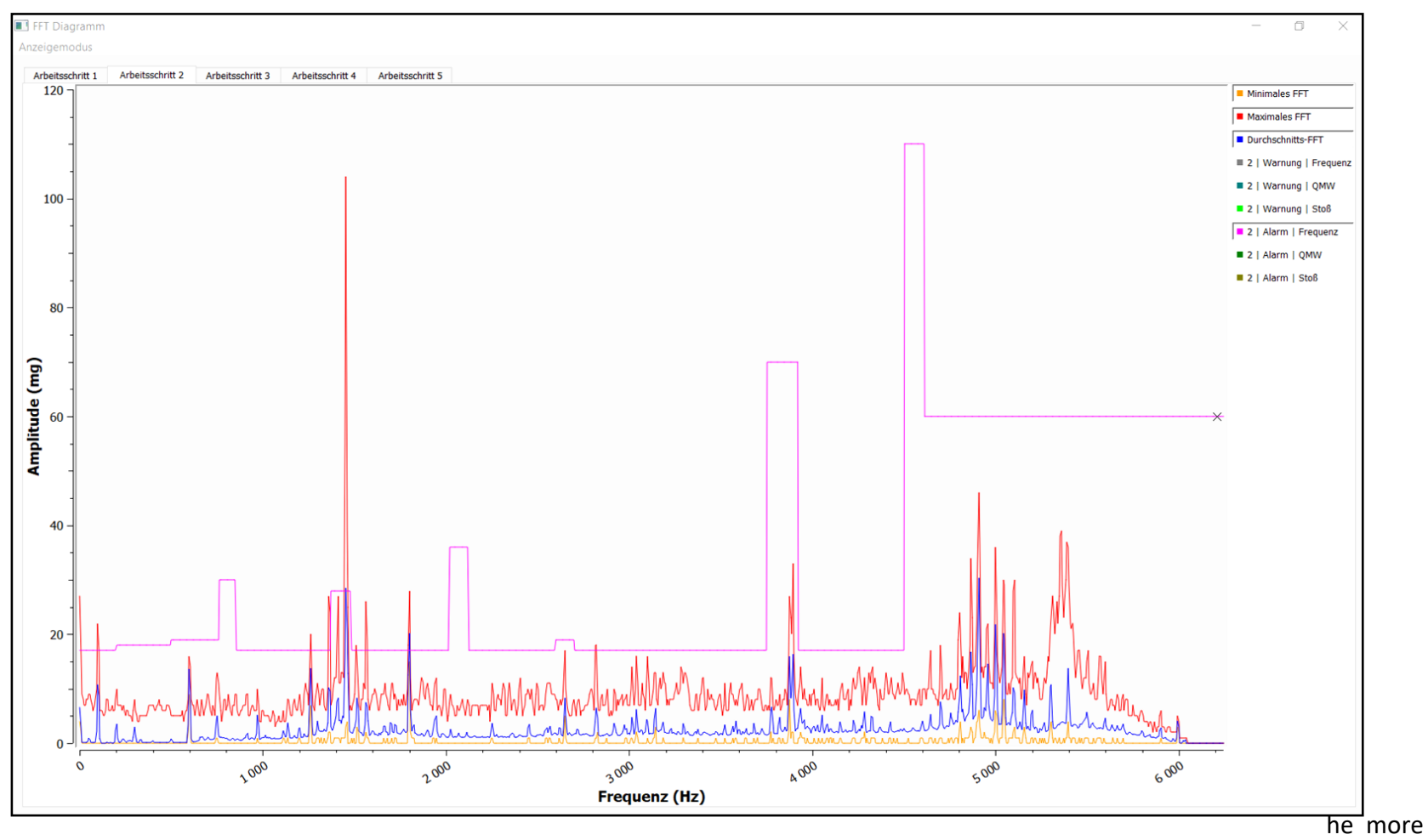

Figure 2. Diagram for NOK part

The system must recognize which values to evaluate as undesirable. First of all, a limit must be set, which when it exceeds the measured frequency, is evaluated as an error. Such a limit is usually entered manually. It can be assigned to a worker who has experience with the given frequencies, has knowledge of the processes and procedures used and is qualified for these tasks.

The limit can be entered for the entire machining process, for individual operations, different for individual bends of the machine, workpiece and tool, or for specific frequencies of one
Such a limit requires preparation and knowledge of the operation. The limit is set according to the available workpiece information. For a more accurate setting, a sample of the measured workpieces that were measured as satisfactory is taken. It is a good idea to sample several dozen workpieces from different periods, if the production conditions allow it. Combine their graphs into one and write a boundary accordingly. It is too good use of knowledge gained in other processes and evaluate which of the assessed frequencies are important for correct evaluation and which are not. 


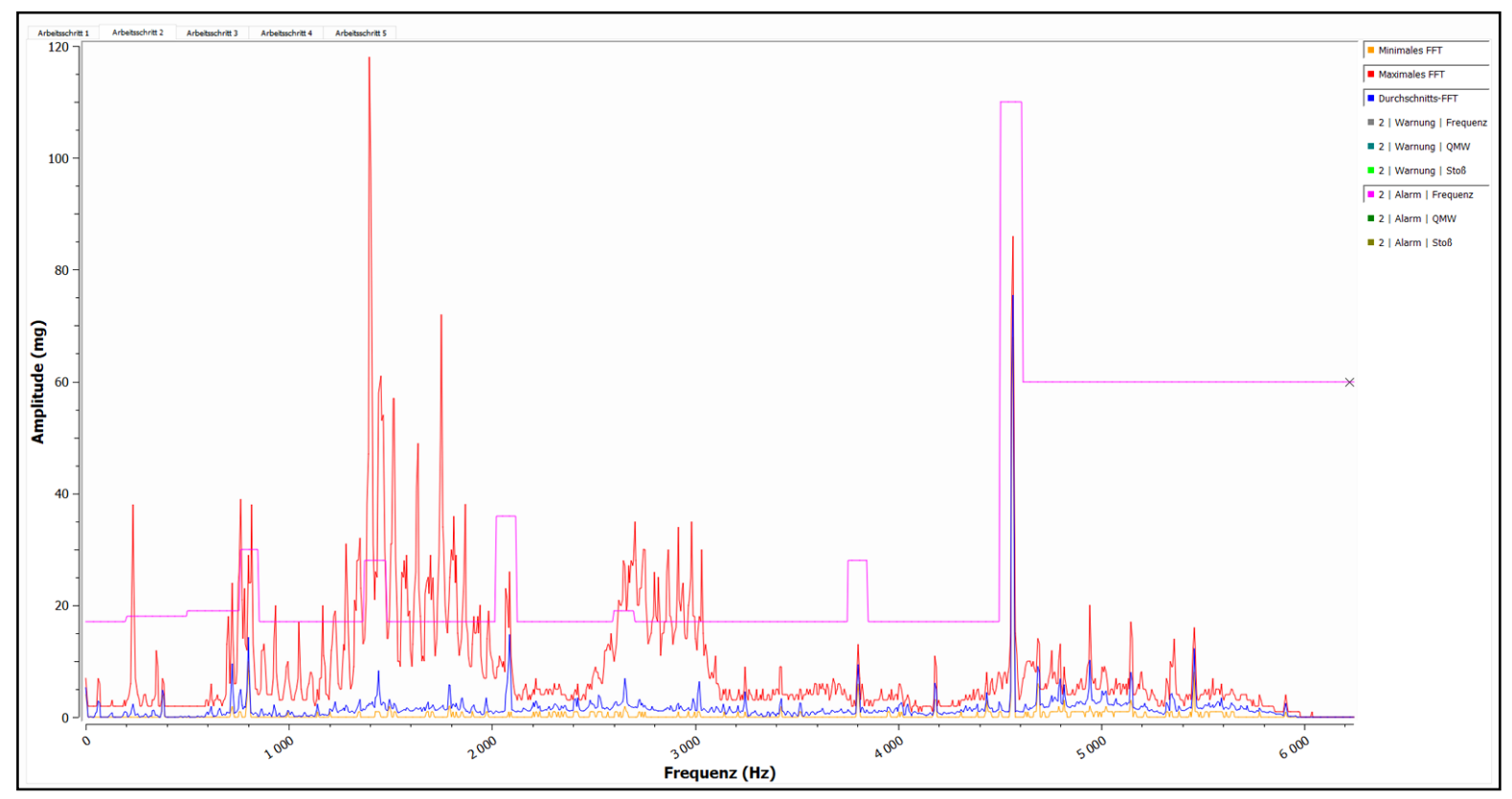

Figure 3. Diagram for NOK part and further actions needed

In our case, we will describe the last variant, and thus the limit is set for the individual frequencies during the process of feeding the workpiece and tool. Three conditions are considered, despite the mentioned two conditions. 1. The condition is an ideal part whose production continues and the worker evaluates it as satisfactory. 2. Condition is a part that is not ideal. During the assessed operation, an unsatisfactory frequency was found that exceeded the specified limit and was evaluated as erroneous. 3. A condition is a course in which the border has been crossed in several places and to a large extent, and the following procedures are needed.

In Figure 1, we can see a graph that shows the first state, which describes a workpiece that meets all the necessary parameters for the next process in production. The border is marked in purple. Certain peaks have been set at the boundary to limit normal production vibrations. Even on an ideal component we can observe an increased value of vibrations as in Figure 1, at a frequency of approximately $4550 \mathrm{~Hz}$, but this does not mean that this component is not satisfactory. Every production process has its vibrations. At frequencies of $800 \mathrm{~Hz}, 1400 \mathrm{hz}$ and $2000 \mathrm{~Hz}$ we can see the increase of the limit and the limit of the increased frequency. Here you enter a tolerance of $20 \%$ which can be changed as required. Sometimes it is up to $50 \%$. It depends on the employee who evaluates the situation. Around the frequency of $3850 \mathrm{~Hz}$ we can notice the limit whose tolerance is much higher than the measured value.

This is due to the limit setting of the elevations of many components, where an increased amplitude may occur at this frequency value, but does not affect the accuracy of the process and its effect on the part being manufactured.

In Figure 2 we can see a graph that describes the second phenomenon. This part was evaluated as unsuitable by the system and was sent among non-compliant pieces. The following measurements should be made on the component and the correctness of the set diagnostics assessed. If we find that the part does not conform when measuring the part, we will take the necessary measures. The diagnostic system was successful and found an error as expected. We can evaluate this as a success. However, if the component undergoes measurements and no defects are found on it, the vibrodiagnostic system must be re-evaluated and the necessary operations must be carried out to prevent such phenomena. This means finding insufficient tolerance of the border and its subsequent change. In this case, however, the part did not comply. If we take a closer look at the graph, we can see a significant crossing of the limit at a frequency of $1400 \mathrm{~Hz}$ by a high value. This is a visible indicator of a faulty component. However, this condition may not always be obvious, or this obvious condition may not be the cause of the part error. Sometimes it can be a small overshoot as at the frequency of $2800 \mathrm{~Hz}$, which we can see in Figure 4.

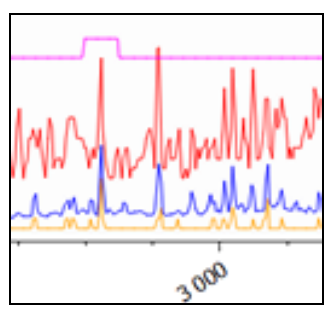

Figure 4. Detail of the failure signal

In Figure 3 we can see a graph that also describes the second phenomenon. As in the previous case, the part was evaluated as unsuitable and sent among the non-compliant pieces. However, when looking at the graph, we can see several limit exceedances at the values of $200 \mathrm{~Hz} 800 \mathrm{~Hz} 1200 \mathrm{~Hz}-2000 \mathrm{~Hz}$ and $2600 \mathrm{~Hz}-3050 \mathrm{~Hz}$ frequencies, which visibly exceed the limit. Without the need for a detailed visual analysis, we can evaluate the undesirable condition of the product and not only that the unwanted condition of the mine also occurred on the machine. This requires more intervention in the production process. The need to measure the part, and perform an inspection of the machine. Workers can be suggested other necessary operations or testing of another piece that has been evaluated as an OK piece. In this particular case, it was necessary to work on the machine and align the production tool. After such an incident, extra care must be taken the next time the device is started. It is important to pay attention to such conditions, as the consequences can be fatal and can trigger a series of adverse effects on production.

\section{CONCLUSIONS}

Diagnostic systems of various kinds are implemented in production spheres in order to obtain information. This information is evaluated and used to create an effective 
network of improvements. Sometimes these systems help in efficiency, speed and overall profit for different businesses. Thanks to these data, we can assess the correctness of production and many times predict phenomena that we would not otherwise predict.

Vibrodiagnostic systems help everyday production to meet the required conditions and make life and work easier for employees. Although this is preceded by the time of preparations, measurements and comparisons, this time must be taken as an investment in the future with the intention of streamlining production. In the case under consideration, we see information on a graph that is not very valuable for the average eye, but after a closer look we can find out more information that can be used in further production. With higher production, we can assess several correct products and set more precise limits with limits lower than $20 \%$ for more efficient diagnostics when assessing incorrect pieces. We also find information about frequencies, and their effects. In this case, we found that frequencies higher than $4600 \mathrm{~Hz}$ are irrelevant to us and do not tend to rise when faulty components occur.

Looking at the graphs of the second state, we also find a lot of interesting information about the behavior of the component from the point of view of vibrations. We see what defects on the components tend to increase values at which frequencies and based on that we can evaluate the defective pieces. After long-term use of vibrodiagnostics, we can reduce the frequency of measured pieces and speed up production and release measuring instruments for other pieces. However, this applies if we can rely on diagnostics, and this will be provided by an experienced worker.

\section{ACKNOWLEDGMENTS}

This work was supported by the project VEGA 1/0226/21 of Scientific Grant Agency of the Ministry of Education, science, research and sport of the Slovak Republic and the Slovak Academy of Sciences.

\section{REFERENCES}

[Balara 2018] Balara, M., Duplakova, D., Matiskova, D. Application of a signal averaging device in robotics. Measurement, 2018, Vol. 115, No. 2, pp. 125-132, Issue 5-8. ISSN 0263-2241.

[Bielousova 2017] Bielousova, R. Developing materials for english for specific purposes online course within the blended learning concept. TEM Journal, 2017, No. 3, pp. 637-642.

[Bozek 2021] Bozek, P., Nikitin, Y., Krenicky, T. Methods, Models, Algorithms for Diagnostics of Mechatronic Systems. Studies in Systems, Decision and Control, 2021, Vol. 345, pp. 17-26.

[Dillinger 2007] Dillinger, J. Moder Engineering for School and Practice. Prague, 2007, 612 p. ISBN 978-80-86706-19-1.

[Duplakova 2018] Duplakova, D., et al. Determination of optimal production process using scheduling and simulation software. Int. J. of Simulation Modelling, 2018, Vol. 17, No. 4, p. 447.

[Dyadyura 2017] Dyadyura, K., et al. Influence of roughness of the substrate on the structure and mechanical properties of TiAIN nanocoating condensed by DCMS. In: Proc. IEEE 7th Int. Conf. on Nanomaterials: Applications and Properties, NAP-2017, 01FNC10, 2017.

[Flegner 2019] Flegner, P., Kacur, J., Durdan, M., Laciak, M. Processing a measured vibroacoustic signal for rock type recognition in rotary drilling technology. Measurement, Journal of the International Measurement Confederation, 2019, Vol. 134, pp. 451-467.

[Flegner 2020] Flegner, P., Kacur, J., Durdan, M., Laciak, M. Statistical Process Control Charts Applied to Rock Disintegration Quality Improvement. Applied sciences, 2020, Vol. 10, No. 23 pp. 1-26.

[Gombar 2013] Gombar, M., Vagaska, A., Kmec, J., Michal, P. Microhardness of the Coatings Created by Anodic Oxidation of Aluminium. Applied Mechanics and Materials, 2013, Vol. 308, pp. 95-100.

[Kreidl 2006] Kreidl, M., Smid R. Technical diagnostics. Prague: BEN, 2006, ISBN 80-7300-158-6.

[Krenicky 2012] T. Krenicky, M. Rimar, M. Monitoring of vibrations in the technology of AWJ. Key Engineering Materials, 2012, Vol. 496, pp. 229-234.

[Macala 2009] Macala, J., Pandova, I., Panda, A. Clinoptilolite as a mineral usable for cleaning of exhaust gases. Mineral resources management, 2009, Vol. 25, No. 4, pp. 23-32.

[Macala 2017] Macala, J., Pandova, I., Panda, A. Zeolite as a prospective material for the purification of automobile exhaust gases. Mineral resources management, 2017, Vol. 33, No. 1, pp. 125-138. ISSN 0860-0953.

[Michalik 2014] Zajac, J., Hatala, M., Mital, D. and Fecova, V. Monitoring surface roughness of thin-walled components from steel C45 machining down and up milling. Measurement, 2014, Vol. 58, pp. 416-428. ISSN 0263-2241.

[Modrak 2019] Modrak, V., Soltysova, Z., Onofrejova, D. Complexity Assessment of Assembly Supply Chains from the Sustainability Viewpoint. Sustainability, 2019, Vol. 11, No. 24, pp. 1-15. ISSN 2071-1050.

[Molnar 2019] Molnar, F. Vibrodiagnostics - Tool of Rotary Machinery Reliability. Tribotechnics, 2019, Vol. 12, No. 4.

[Monkova 2013] Monkova, K., Monka, P. and Jakubeczyova, D. The research of the high speed steels produced by powder and casting metallurgy from the view of tool cutting life. Applied Mechanics and Materials, 2013, Vol. 302, No. 302, pp. 269-274.

[Mrkvica 2012] Mrkvica, I., Janos, M., Sysel, P. Cutting efficiency by drilling with tools from different materials. Advanced Materials Research, 2012, Vols. 538-541, pp. 13271331. ISSN1022-6680.

[Olejarova 2017] Olejarova, S., Dobransky, J., Svetlik, J., Pituk, M. Measurements and evaluation of measurements of vibrations in steel milling process. Measurement: Journal of the International Measurement Confederation, 2017, Vol. 106, pp. 18-25.

[Olejarova 2019] Olejarová, S., Ruzbarsky, J., Krenicky, T. Vibrodiagnostic analysis. SpringerBriefs in Applied Sciences and Technology, 2019, pp. 29-37. ISSN 2191-530X.

[Panda 2014] Panda, A., Duplak, J. Comparison of theory and practice in analytical expression of cutting tools durability for potential use at manufacturing of bearings. Applied Mechanics and Materials, 2014, Vol. 616, pp. 300-307. ISSN 1662-7482.

[Panda 2018a] Panda, A., et al. Advantages and effectiveness of the powder metallurgy in manufacturing technologies. Metallurgy, 2018, Vol. 57, No. 4, pp. 353-356. ISSN 0543-5846.

[Panda 2018b] Panda, A., Olejarova, S., Valicek, J., Harnicarova, M. Monitoring of the condition of turning machine bearing housing through vibrations. International Journal of Advanced Manufacturing Technology, 2018, Vol. 97, No. 1-4, pp. 401-411.

[Panda 2019] Panda, A., et al. Development of the method for predicting the resource of mechanical systems. International Journal of Advanced Manufacturing Technology, 2019, Vol. 105, No. 1-4, pp. 1563-1571. ISSN 0268-3768. 
[Pandova 2018] Pandova, I., et al. Use of sorption of copper cations by clinoptilolite for wastewater treatment. International Journal of Environmental Research and Public Health, 2018, Vol. 15, No. 7, pp. 1-12. ISSN 1661-7827.

[Peterka 2018] Chaus, A.S., et al. Complex fine-scale diffusion coating formed at low temperature on high-speed steel substrate. Applied Surface Science, 2018, Vol. 437, pp. 257-270.

[Pollak 2020a] Polllak, M., Dobransky, J.: Structural design and material cutting using a laser end effector on a robot arm. TEM Journal: Technology, Education, Management, Informatics, 2020, Vol. 9, No. 4, pp. 1455-1459. ISSN 2217-8309.

[Pollak 2020b] Polllak, M., Kocisko, M., Paulisin, D., Baron, P. Measurement of unidirectional pose accuracy and repeatability of the collaborative robot UR5. Advances in Mechanicl Engineering, 2020, Vol. 12, No. 12, pp. 1-21.

[Rimar 2016] Rimar, M., Smeringai, P., Fedak, M., Kuna, S. Technical and software equipment for the real time positioning control system in mechatronic systems with pneumatic artificial muscles. Key Engineering Materials, 2016, Vol. 669, pp. 361369. ISSN 1662-9795.

[Smetana 1998] Smetana C. Noise and Vibrations. Sdělovací technika, Prague 1988, ISBN 80-901936-2-5.

[Straka 2018a] Straka, L., Hasova, S. Optimization of material removal rate and tool wear rate of $\mathrm{Cu}$ electrode in die-sinking EDM of tool steel. Int. J. of Advanced Manufacturing Technology, 2018, Vol. 97, No. 5-8, pp. 2647-2654

[Straka 2018b] Straka, L., Hasova, S. Prediction of the heataffected zone of tool steel EN X37CrMoV5-1 after die-sinking electrical discharge machining. In: Proc. of the institution of mechanical engineers part B - Journal of engineering manufacture, 2018, Vol. 232, No. 8, pp. 1395-1406

[Valicek 2016] Valicek, J., et al. A new approach for the determination of technological parameters for hydroabrasive cutting of materials. Materialwissenschaft und Werkstofftechnik, 2016, Vol. 47, no. 5-6, pp. 462-471.

[Valicek 2017] Valicek, J., et al. Identification of Upper and Lower Level Yield strength in Materials. Materials, 2017, Vol. 10, No. 9, pp. 1-20. ISSN 1996-1944.

[Zaborowski 2007] Zaborowski, T. Ekowytwarzanie. Gorzow, 2007, 100 p.

\section{Contact:}

Prof. Eng. Anton Panda, PhD.

Faculty of Manufacturing Technologies with a seat in Presov,

Technical University of Kosice,

Sturova 31, 080001 Presov, Slovakia

e-mail: anton.panda@tuke.sk 